\title{
Emerging DPP-4 inhibitors: focus on linagliptin for type 2 diabetes
}

This article was published in the following Dove Press journal:

Diabetes, Metabolic Syndrome and Obesity:Targets and Therapy

3 January 2013

Number of times this article has been viewed

\section{Baptist Gallwitz}

Department of Medicine IV, Eberhard-Karls-University Tübingen, Tübingen, Germany
Correspondence: Baptist Gallwitz

Department of Medicine IV, Eberhard-Karls-University Tübingen,

Otfried-Müller Strasse 10,

72976 Tübingen, Germany

Tel +49 707I 2982093

Fax +49 707I 295004

Email baptist.gallwitz@med.uni-tuebingen. de
Abstract: The first dipeptidyl-peptidase-IV (DPP-4) inhibitor for the treatment of type 2 diabetes became available in 2006. Since then, the number of DPP-4 inhibitors has increased and DPP-4 inhibitors have developed into an important drug class. DPP-4 inhibitors act by increasing endogenous GLP-1 and GIP concentrations. Via this mechanism, insulin secretion is glucose-dependently stimulated and glucagon secretion inhibited. This results in a low risk for hypoglycemia. Furthermore, DPP-4 inhibitors are weight-neutral. Linagliptin is a novel DPP-4 inhibitor that, in contrast to the other members of this drug class, is eliminated by a biliary/hepatic route rather than by renal elimination. This property allows the use of linagliptin in type 2 diabetic patients with normal kidney function as well as in patients with renal insufficiency without dose adjustments. In comparative clinical studies, linagliptin was noninferior to other established antidiabetic agents, especially to metformin and sulfonylurea. It showed a superior safety profile over glimepiride regarding hypoglycemia, weight gain, a composite cardiovascular endpoint, and stroke. This review gives an overview on the efficacy and safety of linagliptin in comparison to the classical oral antidiabetic drugs as well as to the other DPP-4 inhibitors.

Keywords: type 2 diabetes, oral antidiabetic drugs, incretin-based therapies, DPP-4 inhibitors, linagliptin

\section{Introduction}

The incidence and prevalence of type 2 diabetes is increasing rapidly, and estimations of the International Diabetes Federation (IDF) have predicted that 552 million patients will be affected by the year $2030 .{ }^{1}$ Type 2 diabetes is a chronic and progressive disease that is characterized by severe and often fatal micro- and macrovascular complications. The complications and the progressive nature of type 2 diabetes result in economic implications that may become a burden for many countries around the world ${ }^{1}$ therefore, effective and safe medications, which are easy to use and to distribute, are needed. In this respect, it is important that these therapies do not require regular and frequent glucose monitoring or monitoring of organ functions with additional laboratory tests (eg, for renal or hepatic function), which would be associated with additional costs.

Dipeptidyl-peptidase-IV (DPP-4) inhibitors were introduced in 2006, with sitagliptin as the first substance, followed by vildagliptin, saxagliptin, linagliptin, and alogliptin. ${ }^{2}$ Due to their efficacy (which is noninferior to sulfonylureas), low risk of hypoglycemia, body-weight neutrality, and mostly once-daily dosing, DPP-4 inhibitors seem to fulfill the aforementioned requirements. Additionally, DPP-4 inhibitors have demonstrated 
a low rate of adverse events and good tolerability. For sitagliptin, saxagliptin, and vildaglitpin, fixed-dose combinations with metformin are already available and planned for the other DPP-4 inhibitors. ${ }^{3}$ The availability of the different DPP-4 inhibitors and their fixed-dose combinations with metformin vary between countries. The fixed-dose combinations have shown good patient adherence. DPP-4 inhibitors have been perceived as an important addition to the treatment algorithm in type 2 diabetes and have been implemented in numerous national guidelines (eg, in Germany). ${ }^{4}$ Only recently, they were placed as second- and third-line therapy among other agents in the recent joint position statement of the American Diabetes Association (ADA) and the European Association for the Study of Diabetes (EASD). ${ }^{5}$

The mechanism of action of DPP-4 inhibitors is based on incretin hormone physiology. The incretin hormones glucagon-like peptide-1 (GLP-1) and gastric inhibitory polypeptide (GIP) are secreted from the intestinal L- and K-cells, respectively, after a meal. With hyperglycemia, insulin secretion is stimulated via these incretin hormones. The phenomenon that orally ingested glucose leads to a higher insulin response than an isoglycemic intravenous glucose administration has been termed "incretin effect;" in humans, GIP and GLP-1 are the most important incretin hormones responsible for this effect. ${ }^{6}$ In type 2 diabetes, the incretin effect is diminished; ${ }^{7}$ however, supraphysiological concentrations of GLP-1 still exert the typical insulinotropic and glucagonostatic actions in a glucose-dependent manner, while GIP loses its insulinotropic action. ${ }^{6,7}$ Both, GLP-1 and GIP have only a very short biological half-life of approximately 1-2 minutes due to their rapid cleavage by the peptidase DPP-4. GLP-1 is the substrate with the highest affinity for DPP-4. ${ }^{8-10}$ DPP-4 inhibitor action leads to an approximately threefold elevation of endogenous GLP-1 plasma concentrations that contribute significantly to the glucose-dependent stimulation of insulin secretion and inhibition of glucagon secretion. ${ }^{6,8}$ The effectiveness of this principle in type 2 diabetic patients was proven in $2002 .{ }^{11}$ Similar to studies with native GLP-1 or GLP-1 receptor agonists, animal studies in rodents with DPP-4 inhibitors have shown an improvement in beta cell function and an increase in beta cell mass. ${ }^{6}$ Most DPP-4 inhibitors are given as a standard once-daily dose, and fixed-dose combinations with metformin are available., , $3,5^{-}$

The DPP-4 inhibitor linagliptin is now approved by the US Food and Drug Administration (FDA) and the European Medicines Agency (EMA), and in many countries worldwide. This article is focused on the efficacy and safety of linagliptin.
Literature was retrieved using Medline, Scopus, and Embase. Further information regarding clinical trials was obtained directly from the clinical study register ClinicalTrials.gov.

\section{Chemistry and characteristics of linagliptin}

The xanthine-based DPP-4 inhibitor BI1356 with a molecular mass of 472.5 Da was developed by Boehringer Ingelheim Pharmaceuticals (Ingelheim, Germany) and later named linagliptin (Figure 1). Linagliptin inhibits DPP-4 competitively and reversibly and shows a slow rate of dissociation from the active center of the DPP-4 enzyme molecule. ${ }^{12}$ In vitro, the maximal efficacy for DPP-4 inhibition by linagliptin is comparable to that of the other DPP-4 inhibitors available today. Comparing linagliptin to sitagliptin, vildagliptin, and saxagliptin with their respective half maximal inhibitory concentration $\left(\mathrm{IC}_{50}\right)$ values for DPP-4 inhibition of $19 \mathrm{nM}$, $62 \mathrm{nM}$, and $50 \mathrm{nM}$, linagliptin demonstrated the lowest $\mathrm{IC}_{50}$ of approximately $1 \mathrm{nM}$ corresponding to the highest potency of DPP-4 inhibition among these compounds. Regarding the selectivity of linagliptin towards DPP-4 in comparison to other enzymes of the DPP family, this is 40,000-fold higher towards DPP-4 than towards DPP-8 and >10,000-fold higher towards DPP-9. Linagliptin and other protease enzymes such as aminopeptidase $\mathrm{N}$ or $-\mathrm{P}$, plasmin, prolyl oligopeptidase, thrombin, and trypsin show hardly any interaction with linagliptin. ${ }^{12}$ Beyond these characteristics, linagliptin does not possess a significant inhibitory effect on the CYP 450 enzymes $\left(\mathrm{IC}_{50}>50 \mu \mathrm{M}\right) .{ }^{13,14}$

\section{Pharmacokinetics, pharmacodynamics, and drug-drug interactions of linagliptin}

In animal studies, linagliptin demonstrated an oral bioavailability and a biological half-life of $51 \%$ and 36 hours, respectively. ${ }^{13,15}$ The bioavailability of linagliptin in humans

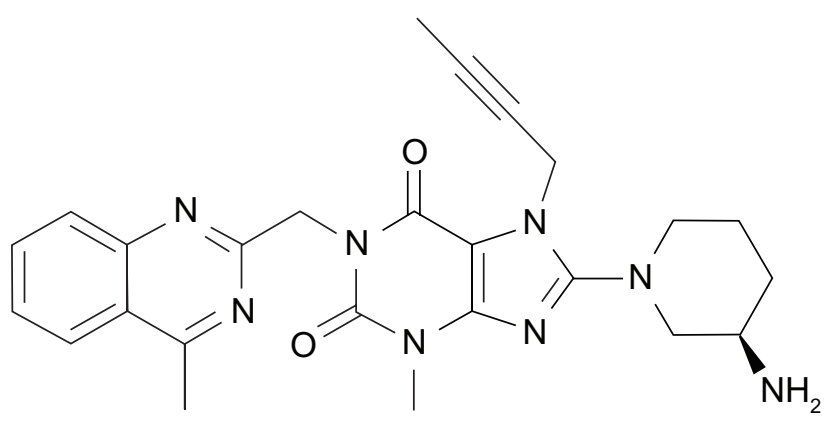

Figure I Molecular structure of linagliptin. 
is about $30 \%$ and is lower than that of vildagliptin (85\%) or sitagliptin (approximately 87\%). ${ }^{16-18}$ Linagliptin is rapidly absorbed after oral administration with a $\mathrm{T}_{\text {max }}$ of $0.7-3$ hours that does not differ between healthy and type 2 diabetic subjects after single and multiple doses. The elimination of linagliptin is slow, with a half-life of 70-80 hours for doses $<50 \mathrm{mg} .{ }^{19}$ Linagliptin is hardly metabolized in vivo and $\sim 90 \%$ is excreted unmetabolized via the feces by a hepatobiliary route..$^{20,21}$ Only $1 \%-6 \%$ is eliminated via a renal route when standard doses of $5 \mathrm{mg}$ linagliptin are given. ${ }^{19,21,22}$ A high proportion of binding to plasma proteins has been observed and, at therapeutic concentrations, linagliptin is almost completely plasma protein-bound. ${ }^{21}$ Linagliptin demonstrated high-affinity binding to DPP-4 resulting in a long biological half-life, predominantly in the kidney, where DPP-4 expression is high. Because the tissue-binding capacity is limited at low doses already, tissue accumulation of linagliptin does not occur after multiple oral administration. ${ }^{20}$ Steady-state concentrations are reached after 2-5 days of once-daily administration of linagliptin. In clinical studies in different ethnic groups, only modest drug accumulation and an elimination half-life of between 113 and 130 hours was observed. ${ }^{16,23}$ The plasma DPP-4 activity was already inhibited effectively by $73 \%$ after doses of $2.5 \mathrm{mg}$ linagliptin with a maximal DPP-4 inhibition observed between 0.7 and 3.0 hours after administration. DPP-4 inhibition was found to be sustained for up to 96 hours. At linagliptin plasma concentrations of $10 \mathrm{nM}$, a complete inhibition of plasma DPP-4 was shown. The $50 \%$ and $80 \%$ inhibitory doses for linagliptin were calculated to be in the ranges of 2-4 and 4-6 nM, respectively. ${ }^{16,19,23}$ Linagliptin given once daily to patients with type 2 diabetes led to a maximal DPP-4 inhibition of $90 \%$ with doses of $5 \mathrm{mg}$ and $10 \mathrm{mg}$ at steady state, with approximately $85 \%$ inhibition still remaining 24 hours post-dose. Plasma concentrations of intact GLP-1 concomitantly increased about threefold and glucose concentrations consequently improved. ${ }^{22}$

Linagliptin is not metabolized by CYP 450 and therefore does not interfere with drugs metabolized by this enzyme. ${ }^{13,21}$ The potential interactions of linagliptin and metformin were investigated, since metformin is the drug most frequently used in combination with linagliptin. In a study in healthy volunteers, no interaction between the substances was observed that would change the efficacy or kinetics of linagliptin to inhibit DPP-4, on the one hand, or that would change the pharmacokinetics or -dynamics of metformin, on the other. Therefore metformin and linagliptin can be safely administered in a combination therapy without dose adjustments. ${ }^{24}$ Likewise, no relevant drug-drug interactions between linagliptin and pioglitazone were detected in healthy subjects, also allowing this drug combination to be used without dose adjustments for either linagliptin or pioglitazone. ${ }^{25}$ No clinically significant changes in the pharmacokinetics of digoxin were observed in combination with linagliptin in healthy subjects. Thus, linagliptin most likely has no influence on the activity of P-glycoprotein or other transporters relevant for digoxin pharmacokinetics; therefore, dose adjustments would also not be necessary in a combination therapy with linagliptin and digoxin. ${ }^{26}$

The combination of sulfonylurea glyburide and linagliptin was investigated in a randomized, open-label, cross-over study with three periods in healthy subjects to study the possible effects of linagliptin on the pharmacokinetics of glyburide and vice versa. The co-administration of single doses of $1.75 \mathrm{mg}$ glyburide daily to $5 \mathrm{mg}$ of linagliptin did not significantly change the steady-state pharmacokinetics and $\mathrm{C}_{\max }$ of either drug. ${ }^{27}$

The potential drug-drug interactions between the novel sodium glucose cotransporter-2 (SGLT-2) inhibitor BI10773 (empagliflozin) and linagliptin was investigated in healthy volunteers. The combined administration of linagliptin $(5 \mathrm{mg} / \mathrm{d})$ had no effect on the extent of empagliflozin absorption given with a once daily dose of $50 \mathrm{mg}$ (area under the curve $[\mathrm{AUC}]_{\hat{\mathrm{o}} \mathrm{ss}}$ geometric mean ratio [GMR] 101.7\%; 90\% confidence interval [CI]: 96.5\%-107.2\%). There was a slight but clinically nonsignificant reduction in the rate of absorption (C $\mathrm{C}_{\text {max,ss }}$ GMR 88.3\%; 90\% CI: 78.8\%-98.9\%) of empagliflozin. Co-administration of empagliflozin had no effect on the extent $\left(\mathrm{AUC}_{\hat{\mathrm{o}} \mathrm{ss}} \mathrm{GMR} 103.3 \%\right.$; 90\% CI: 96.1\%-111.1\%) or the rate $\left(\mathrm{C}_{\text {max,ss }}\right.$ GMR $101.5 \%$; 90\% CI: 86.9\%-118.5\%) of linagliptin absorption. Empagliflozin alone and in combination with linagliptin led to a clinical relevant excretion of glucose in urine as expected with this SGLT-2 inhibitor. DPP-4 inhibition was also not affected by empagliflozin administration. Both drugs were well tolerated. These data support co-administration of empagliflozin and linagliptin in future clinical trials without dose adjustments of either compound. ${ }^{28}$

\section{Clinical studies with linagliptin in the Phase III program Monotherapy studies}

Table 1 gives an overview of the Phase III clinical studies performed with linagliptin.

In obese patients with type 2 diabetes and a baseline $\mathrm{HbA}_{1 \mathrm{c}}$ ranging from $6.8 \%-7.3 \%$, GLP-1 plasma concentrations were raised up to fourfold during meal tests with linagliptin administration in a randomized, double-blind, 


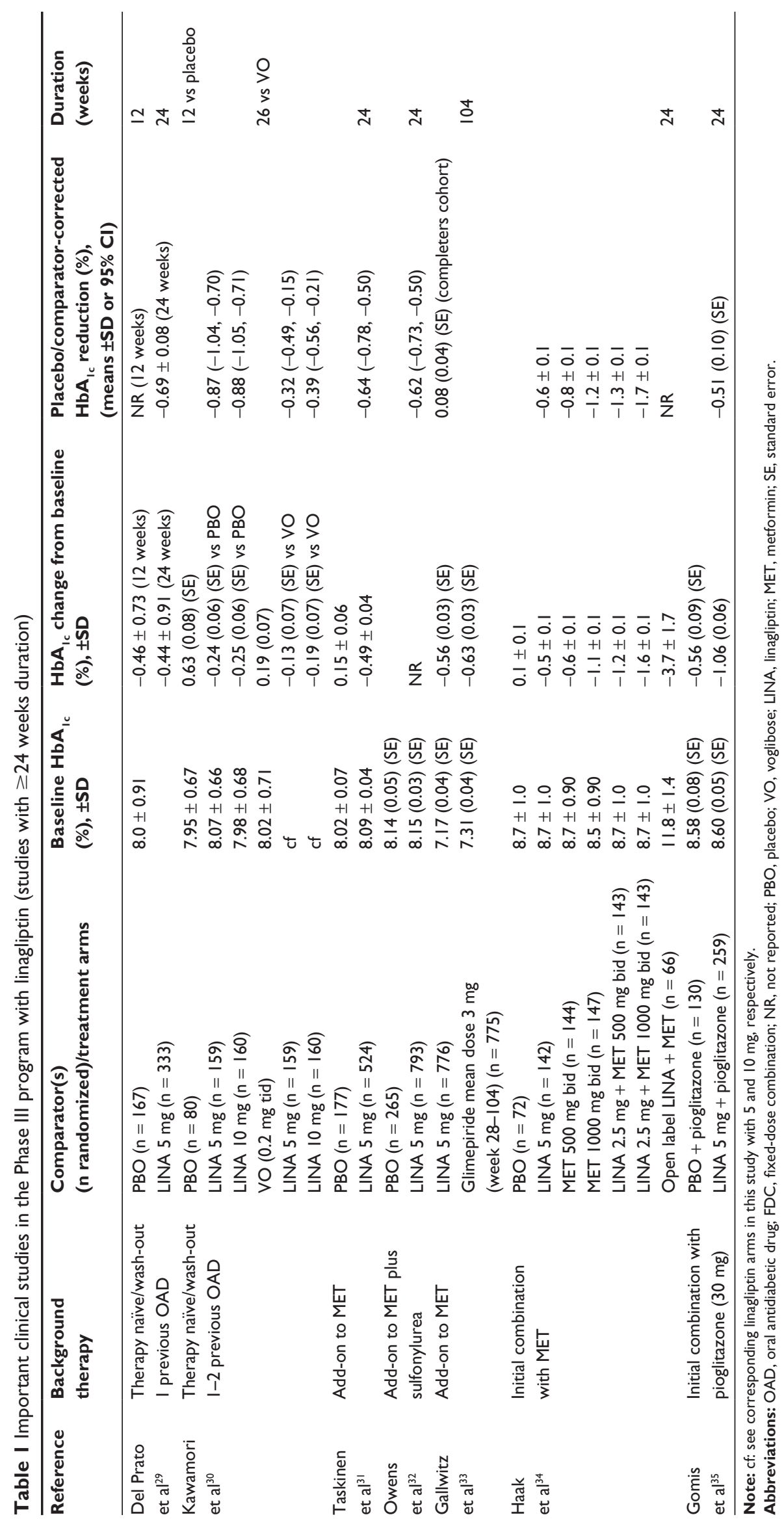


placebo-controlled trial. Plasma glucagon was suppressed by $24 \%$. As a result of these effects, linagliptin therapy resulted in a significant reduction of the meal-related glucose excursions. The placebo-corrected reductions of $\mathrm{HbA}_{1 \mathrm{c}}$ were $-0.31 \%,-0.37 \%$, and $-0.28 \%$ for the doses of $2.5 \mathrm{mg}$, $5 \mathrm{mg}$, and $10 \mathrm{mg}$ linagliptin, respectively. ${ }^{16}$

In Japanese patients, a similar study design demonstrated comparable results, with placebo-subtracted $\mathrm{HbA}_{1 \mathrm{c}}$ reductions of $0.27 \%, 0.27 \%$, and $0.42 \%$ for the doses of $2.5 \mathrm{mg}$, $5 \mathrm{mg}$, and $10 \mathrm{mg}$ linagliptin after 4 weeks of treatment. ${ }^{16,23}$

In drug-naïve type 2 diabetic patients or patients who had been washed out from their previous oral antidiabetic treatment for 6 weeks, a once-daily dose of $5 \mathrm{mg}$ linagliptin significantly reduced the $\mathrm{HbA}_{1 \mathrm{c}}$ by $-0.69 \%$ (placebo-corrected) after 24 weeks $(P<0.0001)$. The patients with a baseline $\mathrm{HbA}_{1 \mathrm{c}} \geq 9 \%$ demonstrated an even greater reduction in $\mathrm{HbA}_{1 \mathrm{c}}(-1.01 \%, P<0.0001)$. Along with the $\mathrm{HbA}_{1 \mathrm{c}}$ reductions, the fasting plasma glucose concentrations and 2-hour postprandial glucose values also improved significantly $(-1.3 \mathrm{mmol} / \mathrm{L}, P<0.0001$ and $-3.2 \mathrm{mmol} / \mathrm{L}, P<0.0001$, respectively). Parameters for beta cell function also improved significantly compared to placebo: homeostasis model assessment (HOMA)- $\beta(P=0.049)$; disposition index $(P=0.0005)$; and proinsulin/insulin ratio $(P=0.025){ }^{29}$

In Japanese patients with type 2 diabetes, the efficacy of daily doses of either $5 \mathrm{mg}$ or $10 \mathrm{mg}$ of linagliptin were compared to placebo or voglibose treatment. The adjusted mean treatment differences at week 12 were $-0.87 \%(95 \%$ CI: -1.04 to $-0.70, P<0.0001)$ and $-0.88 \%(95 \% \mathrm{CI}:-1.05$ to $-0.71, P<0.0001$ ) for linagliptin 5 and $10 \mathrm{mg}$ versus placebo. At week 26 these differences were $-0.32 \%(95 \%$ CI: -0.49 to $-0.15, P=0.0003)$ and $-0.39 \%$ (95\% CI: -0.56 to $-0.21, P<0.0001$ ) for linagliptin 5 and $10 \mathrm{mg}$ versus voglibose. At week 12, the mean $\mathrm{HbA}_{1 \mathrm{c}}$ was $7.58 \%$, 7.48\%, and $8.34 \%$ in patients receiving linagliptin $5 \mathrm{mg}$, linagliptin $10 \mathrm{mg}$, and placebo, respectively. At week 26, the mean $\mathrm{HbA}_{1 \mathrm{c}}$ was $7.63 \%$ with linagliptin $5 \mathrm{mg}, 7.50 \%$ with linagliptin $10 \mathrm{mg}$, and $7.91 \%$ with voglibose. There was no significant difference in drug-related adverse event rates across the different treatment arms over the whole 26-week study period (11.3\% linagliptin $5 \mathrm{mg}, 10.6 \%$ linagliptin $10 \mathrm{mg}$, and $18.5 \%$ voglibose) and, most importantly, there were no documented episodes of hypoglycemia. ${ }^{30}$

\section{Studies with linagliptin as an add-on to metformin}

In patients not adequately controlled with metformin monotherapy, a 24-week study investigated the efficacy and safety of a daily dose of $5 \mathrm{mg}$ linagliptin compared to placebo. Linagliptin significantly reduced the $\mathrm{HbA}_{1 \mathrm{c}}$ in this study from a baseline of $8.1 \%$ by $-0.49 \%$ compared to the placebo group, in which the $\mathrm{HbA}_{1 \mathrm{c}}$ reduction observed was only $-0.155 \%$. Accordingly, the fasting and postprandial plasma glucose levels were also reduced significantly (fasting glucose baseline $9.4 \mathrm{mmol} / \mathrm{L} ;-0.59$ for the linagliptin add-on group, vs $+0.58 \mathrm{mmol} / \mathrm{L}$ for the placebo group, $P<0.0001$; 2-hour postprandial glucose -2.7 for linagliptin vs $1.0 \mathrm{mmol} / \mathrm{L}$ for placebo, $P<0.0001)$. Hypoglycemic events occurred rarely, with an incidence of $0.6 \%$ in linagliptin-treated patients and $2.8 \%$ in the placebo-treated patients. In both arms, body weight did not change significantly $(-0.4 \mathrm{~kg}$ in the linagliptin arm, $-0.5 \mathrm{~kg}$ in the placebo arm). ${ }^{31}$

Linagliptin was also studied in a triple combination as addon to an existing oral combination therapy with metformin and a sulfonylurea in patients with a baseline $\mathrm{HbA}_{1 \mathrm{c}}$ between $7.0 \%$ and $10.0 \%$. At study end, after 24 weeks, the linagliptinadjusted and placebo-corrected mean change from baseline $\mathrm{HbA}_{1 \mathrm{c}}$ was $-0.62 \%$ (95\% CI: -0.73 to $\left.-0.50 \%, P<0.0001\right)$. Fasting plasma concentrations were was reduced by linagliptin relative to placebo $(-0.7 \mathrm{mmol} / 1,95 \% \mathrm{CI}:-1.0$ to -0.4 , $P<0.0001)$. Improvements in beta-cell function were seen with linagliptin when measured with the HOMA model $(P<0.001)$. The occurrence of severe adverse events was low in both groups (linagliptin $2.4 \%$; placebo $1.5 \%$ ) and, in most cases, due to severe hypoglycemia, which was less frequent in the linagliptin group. Symptomatic hypoglycemia occurred in $16.7 \%$ and $10.3 \%$ of the linagliptin and placebo groups, respectively. Hypoglycemia was generally mild or moderate; severe hypoglycemia was reported in $2.7 \%$ and $4.8 \%$ of the participants experiencing hypoglycemic episodes in the linagliptin and placebo groups, respectively. The most common nonmetabolic adverse events were infections and infestations (upper respiratory tract infection, urinary tract infection, nasopharyngitis); here, a lower incidence was observed in the linagliptin group ( $28.9 \%$ vs $21.5 \%$, placebo vs linagliptin). No significant weight changes were noted. ${ }^{32}$

A 2-year study compared the efficacy and safety of linagliptin as add-on to metformin with that of glimepiride. Patients not well controlled on metformin monotherapy with a baseline $\mathrm{HbA}_{1 \mathrm{c}}$ of $7.7 \%$ received either a standard dose of $5 \mathrm{mg}$ linagliptin once daily $(\mathrm{n}=764)$ or an average dose of $2.45 \mathrm{mg}$ glimepiride once daily $(\mathrm{n}=755)$. Glimepiride was titrated within a $1-4 \mathrm{mg}$ dose range and reached a plateau at $3.0 \pm 1.2 \mathrm{mg}$ (standard deviation) from weeks 28-104. The respective reductions in $\mathrm{HbA}_{1 \mathrm{c}}$ were comparable in the linagliptin $(-0.16 \% \pm 0.03 \%)$ and glimepiride groups 
$(-0.36 \% \pm 0.03 \%$; difference $0.20 \%, 97.5 \%$ CI: $0.09-0.30)$, meeting the predefined noninferiority criterion of $0.35 \%$. Both treatment groups had adjusted mean decreases in the fasting plasma concentrations after 2 years with a treatment difference of $0.35 \mathrm{mmol} / \mathrm{L}$ (95\% CI: $0.14-0.57, P=0.0012$, $<0.05$ [two-sided]). The hypoglycemia incidence was much lower with linagliptin than with glimepiride $(7.5 \%$ vs $36.1 \%, P<0.0001)$. The incidence of severe hypoglycemia was also significantly lower ( 1 incident $[<1 \%]$ vs 12 incidents [2\%]) with linagliptin compared with glimepiride. Additionally, body weight decreased with linagliptin and increased with glimepiride $(-1.4 \mathrm{~kg}$ vs $+1.3 \mathrm{~kg}$; adjusted mean difference $-2.7 \mathrm{~kg}, P<0.0001)$. Linagliptin was associated with significantly fewer cardiovascular events (12 vs 26 patients; relative risk [RR] 0.46, 95\% CI: $0.23-0.91$, $P=0.0213)$. The reduction in cardiovascular events was mainly attributable to a significantly lower number of nonfatal strokes in the linagliptin-treated group (RR 0.27, 95\% CI: $0.08-0.97, P=0.0315$; linagliptin vs glimepiride, respectively) that was not related to hypoglycemic events. ${ }^{33}$

\section{Studies with linagliptin in initial combinations with other oral antidiabetic agents}

An initial combination of metformin and linaglitpin was investigated in a study including an open arm for patients with poor glycemic control. The study (791 patients in total) had six treatment arms with two arms being treated with a free combination of linagliptin $(2.5 \mathrm{mg}$ linaglitpin plus $500 \mathrm{mg}$ metformin, both twice daily, or $2.5 \mathrm{mg}$ linaglitpin plus $1000 \mathrm{mg}$ metformin, both twice daily). The other four arms were monotherapy arms with linagliptin $5 \mathrm{mg}$ once daily, metformin $500 \mathrm{mg}$ or $1000 \mathrm{mg}$ twice daily, or placebo, respectively. Patients $(n=66)$ with a baseline $\mathrm{HbA}_{1 \mathrm{c}}=11 \%$ received an open-label combination therapy with linagliptin $2.5 \mathrm{mg}$ plus metformin $1000 \mathrm{mg}$, both twice daily. The study had six arms, five of which were patients without poor control $\left(\mathrm{HbA}_{1 \mathrm{c}}\right.$ range $8.5 \%-8.7 \%$ at baseline). The sixth arm was an arm of patients with poor control $\left(\mathrm{HbA}_{1 \mathrm{c}}>11.0 \%\right.$; not randomized, but treated in an open arm) with an initial $\mathrm{HbA}_{1 \mathrm{c}}$ of $11.8 \%$. For the initial combination of linagliptin (2.5 mg linagliptin plus $500 \mathrm{mg}$ metformin, both twice daily, or $2.5 \mathrm{mg}$ linaglitpin plus $1000 \mathrm{mg}$ metformin, both twice daily) the placebo-corrected reduction in $\mathrm{HbA}_{1 \mathrm{c}}$ amounted to $-1.3 \%$ and $-1.7 \%$, respectively. The combination therapy was superior to the monotherapy treatments. In the poorly controlled open-label arm, the $\mathrm{HbA}_{1 \mathrm{c}}$ reduction was $-3.7 \%$. The adverse event rate was low and similar to other studies with linaglitpin. The hypoglycemia rate observed with combination treatment was low ( $1.8 \%$, five patients receiving the initial combination). The linagliptin/metformin combination was weight neutral $(-0.23 \mathrm{~kg}$ in the group with $2.5 \mathrm{mg}$ linagliptin and $1000 \mathrm{mg}$ metformin, both twice daily). ${ }^{34}$

Pioglitazone and linagliptin in an initial combination were investigated in a 24-week study with a total of 389 patients in a three-arm study who received either the combination of $30 \mathrm{mg}$ pioglitazone with $5 \mathrm{mg}$ linagliptin once daily, $30 \mathrm{mg}$ pioglitazone as monotherapy, or placebo. After 24 weeks' treatment, $\mathrm{HbA}_{1 \mathrm{c}}$ was reduced by $-1.06 \%$ in the patients with the initial combination therapy, whereas the patients on pioglitazone monotherapy showed an $\mathrm{HbA}_{1 \mathrm{c}}$ reduction of $-0.56 \%$. The reductions of fasting plasma concentrations were significantly greater for linagliptin plus pioglitazone than with placebo plus pioglitazone $(-1.8$ and $-1.0 \mathrm{mmol} / \mathrm{L}$, respectively), corresponding to a treatment difference of $-0.8 \mathrm{mmol} / \mathrm{L}(95 \%$ CI: -1.2 to $-0.4, P<0.0001)$. The rate of mild hypoglycemic events was low, at $1.2 \%$, and all episodes occurred in the linagliptin plus pioglitazone group; no severe hypoglycemia was reported. Additionally, HOMA-insulin resistance (HOMA-IR) and the disposition index as parameters of beta-cell function improved compared to placebo. At the end of the 24-week study, HOMA-IR was -2.9 for linaglitpin plus pioglitazone and -2.58 for placebo plus pioglitazone. The difference between the linagliptin and placebo arms was $-0.32(95 \% \mathrm{CI}$ : -0.77 to $0.13, P=0.16$ ). The ratio of relative change in geometric mean HOMA-IR showed a difference for linagliptin plus pioglitazone versus placebo plus pioglitazone of 0.85 (95\% CI: $0.75-0.96, P=0.0076)$. The adjusted mean change from baseline in HOMA- $\beta$ ( -2.17 for linagliptin plus pioglitazone and -1.44 for placebo plus pioglitazone) was $-0.73(95 \%$ CI: -9.16 to $7.70, P=0.86$ ). The geometric mean for the relative change in the linagliptin plus pioglitazone and placebo plus pioglitazone arms was 1.01 (95\% CI: 0.89 to $1.16, P=0.85$ ). The disposition index increased in both groups: the adjusted mean change from baseline for linagliptin plus pioglitazone was 6.56 , and 3.87 for placebo plus pioglitazone, equivalent to a difference of $2.69(95 \% \mathrm{CI}: 0.65-4.74, P=0.10){ }^{35}$

\section{Safety aspects of linagliptin}

Linagliptin was well tolerated and not associated with specific side effects in doses up to 100-fold of the therapeutic dose of $5 \mathrm{mg}$ in clinical studies. The most frequently reported adverse events (linagliptin vs placebo) were headache ( $21 \%$ vs $38 \%$ ), influenza-like illness ( $11 \%$ vs $4 \%$ ), and nausea ( $4 \%$ vs $6 \%$ ). No changes in laboratory parameters have been observed in the clinical studies nor since approval, so far. In general, 
hypoglycemia rates were similar with linagliptin (8.2\%) and placebo $(5.1 \%)$ in a large meta-analysis of studies with linaglitpin including 3572 patients (2523 treated with linagliptin and 1049 on placebo, mean drug exposure for linagliptin $155 \pm 34.9$ days, $150 \pm 40.2$ for placebo). ${ }^{36}$ The incidence of hypoglycemia was increased in patients with background sulfonylurea therapy (linagliptin 20.7\%), comparable with other reports in which DPP-4 inhibitors were added to a sulfonylurea therapy. Overall, the hypoglycemic event rate with linagliptin was very low (1.0\%) when used without sulfonylureas. ${ }^{16,19,36}$ In a large pooled analysis, incidence rates of adverse events or serious adverse events with linagliptin were comparable to placebo (adverse events $55.0 \%$ vs $55.8 \%$; serious adverse events $2.8 \%$ vs $2.7 \%$ ). The overall aggregated infection rates were $19.5 \%$ for linagliptin and $21.4 \%$ for placebo. Fewer or similar rates of adverse events versus placebo were seen with linagliptin for upper respiratory tract infection (3.3\% vs 4.9\%), headache $(2.9 \%$ vs $3.1 \%)$, urinary tract infection $(2.2 \%$ vs $2.7 \%)$, blood and lymphatic disorders ( $1.0 \%$ vs $1.2 \%)$, hypersensitivity $(0.1 \%$ vs $0.1 \%)$, hepatic enzyme increase $(0.1 \%$ and $0.1 \%$ ), and serum creatinine increase $(0.0 \%$ and $0.1 \%)$. There was a slight increased frequency of nasopharyngitis (5.9\% vs $5.1 \%$ ) and cough (1.7\% vs $1.0 \%)$ with linagliptin. This meta-analysis provides further evidence that linagliptin is well tolerated; similar data are continually being generated. ${ }^{36}$

\section{Potential nonglycemic beneficial effects of linagliptin}

The first animal studies in models of inflammatory bowel disease show that DPP-4 inhibitors may have antiinflammatory properties. ${ }^{37}$ This effect is possibly mediated via T-cell regulation or the inhibition of degradation of glucagon-like peptide-2 (GLP-2), which favors proliferation and repair of the colonic mucosa. In this respect, the anti-inflammatory effects of linagliptin were investigated in a model of acute dextran sulfate sodium (DSS)-induced colitis in BALB/c mice. Treatment with linagliptin did not significantly alter colon length, histology, occult blood in the feces, or stool consistency, all of which were significantly worsened by DSS administration in the animals. Linagliptin significantly reduced pro-inflammatory cytokines, elevated active GLP-2 levels, and reduced clinical changes in DSStreated animals.

In the rodent model of ob/ob mice, linagliptin demonstrated a beneficial effect on wound healing. Immunohistochemistry and immunoblots show a strong expression of DPP-4 in skin from healthy and diabetic (ob/ob) mice. The regulation of DPP-4 protein in the skin seems to indicate a functional basis of a potentially positive action of linagliptin in general wound-healing processes. ${ }^{38}$

Nonalcoholic fatty liver disease (NAFLD) and hepatic steatosis are frequently observed in type 2 diabetes. Treatment of the DIO mice (diet induced obesity mice) with linagliptin improved glycemic parameters and reduced the liver fat content measured by MRS (magnetic resonance spectroscopy). Histological examination revealed significantly less hepatic steatosis and inflammation in the linagliptin-treated group in comparison to control mice. These findings may support the use of linagliptin in patients with type 2 diabetes as well as NAFLD, but clinical studies will have to be performed to challenge this hypothesis. ${ }^{39}$

Artificial myocardial ischemia in rats was used to investigate potential cardiovascular effects of linagliptin. A significant reduction of infarcted tissue and infarction size was observed with linagliptin administration that was followed by a significant elevation of endogenous GLP-1 plasma concentrations. ${ }^{40}$

No significant changes of lipids and blood pressure in clinical trials with linagliptin were observed in a prespecified, prospective, and adjudicated meta-analysis of the Phase III clinical study program involving 5239 patients (2060 treated with linagliptin, median period on linagliptin 175 days). ${ }^{41}$

\section{Perspectives for linagliptin}

DPP-4 inhibitors are an important drug class that can be safely used in patients failing on metformin therapy or on a two-drug oral antidiabetic regime. Combining a DPP-4 inhibitor that acts on insulin and glucagon secretion with metformin that acts on insulin resistance gives the opportunity to address complementary modes of action. Patients with a modestly elevated $\mathrm{HbA}_{1 \mathrm{c}}$ who will reach their therapeutic goal with the addition of another oral drug will especially profit from additional therapy with a DPP-4 inhibitor. This treatment escalation has already been implemented in the recent position statement of the ADA and the EASD. ${ }^{4}$ It is easy to use in clinical practice due to the standard dose for the DPP-4 inhibitor. It furthermore bears the advantage of significantly less hypoglycemic risk compared to sulfonylurea or insulin therapy as well as weight neutrality, unlike in treatment with sulfonylurea, pioglitazone, or insulin.

The DPP-4 inhibitors developed so far have different characteristics regarding their specific pharmacodynamics and pharmacokinetics as well as in their potency. Presently, sufficient data from head-to-head studies comparing the different DPP-4 inhibitors, in order to assess if there are 
specific advantages of one agent versus another, are missing. Since linagliptin is a substance that was developed later than other DPP-4 inhibitors, less comparative data are available than for other compounds of the DPP-4 inhibitor class. Linagliptin is unique regarding its pharmacokinetic profile with strong binding to proteins and strong binding to DPP-4 and a long elimination half-life. So far, linagliptin is the only DPP-4 inhibitor with a non-renal route of excretion. The nonrenal route of excretion is based on its chemical structure and on the high degree of protein-binding in plasma and tissues. Linagliptin can therefore be used without dose adjustment in patients with renal impairment, in contrast to the other available DPP-4 inhibitors. On the other hand, the hepatic route of elimination for linagliptin may make dose adjustment necessary in patients with hepatic failure. Linagliptin itself is hardly metabolized and has no interaction with CYP450. For this reason, pharmacokinetic interference with other agents that are metabolized by the liver is unlikely. ${ }^{14,42}$ This is important for the high number of patients at risk of or with already existing renal impairment common in type 2 diabetes. Similarly, these characteristics of linagliptin may be favorable for older patients with declining renal function. In addition, linagliptin has demonstrated a profile of potential pleiotropic effects that may translate into clinical benefits. The expected cardiovascular outcome data from the CAROLINA study, to be completed in the second half of this decade, will show the value of this DPP-4 inhibitor in comparison to the sulfonylurea glimepiride that is widely used today. ${ }^{42-44}$

\section{Disclosure}

The author is a member of advisory boards for AstraZeneca, Bristol-Myers Squibb, Boehringer Ingelheim (manufacturer of linagliptin), Eli Lilly, Novartis, Novo Nordisk, Merck, Roche, Sanofi, and Takeda, and has also received honoraria from these companies for giving lectures.

\section{References}

1. The Global Burden [webpage on the Internet]. Brussels: International Diabetes Federation (IDF); 2011. Available from: http://www.idf.org/ diabetesatlas/5e/the-global-burden. Accessed 18 December, 2012.

2. Gallwitz B. Sitagliptin: profile of a novel DPP-4 inhibitor for the treatment of type 2 diabetes (update). Drugs Today (Barc). 2007;43:801-814.

3. Gallwitz B. Sitagliptin with metformin: profile of a combination for the treatment of type 2 diabetes. Drugs Today (Barc). 2007;43:681-689.

4. Inzucchi SE, Bergenstal RM, Buse JB, et al. Management of hyperglycaemia in type 2 diabetes: a patient-centered approach. Position statement of the American Diabetes Association (ADA) and the European Association for the Study of Diabetes (EASD). Diabetologia. 2012;55: $1577-1596$

5. German Diabetes Association; Matthaei S, Bierwirth R, Fritsche A, et al. Medical antihyperglycaemic treatment of type 2 diabetes mellitus: update of the evidence-based guideline of the German Diabetes Association. Exp Clin Endocrinol Diabetes. 2009;117:522-557.
6. Drucker DJ, Nauck MA. The incretin system: glucagon-like peptide-1 receptor agonists and dipeptidyl peptidase- 4 inhibitors in type 2 diabetes. Lancet. 2007;368:1696-1705.

7. Nauck MA, Heimesaat MM, Orskov C, Holst JJ, Ebert R, Creutzfeldt W. Preserved incretin activity of glucagon-like peptide 1 [7-36 amide] but not of synthetic human gastric inhibitory polypeptide in patients with type-2 diabetes mellitus. J Clin Invest. 1993;91:301-307.

8. Deacon CF, Hughes TE, Holst JJ. Dipeptidyl peptidase IV inhibition potentiates the insulinotropic effect of glucagon-like peptide 1 in the anesthetized pig. Diabetes. 1998;47:764-769.

9. Mentlein R, Gallwitz B, Schmidt WE. Dipeptidyl-peptidase IV hydrolyses gastric inhibitory polypeptide, glucagon-like peptide-1(7-36)amide, peptide histidine methionine and is responsible for their degradation in human serum. Eur J Biochem. 1993;214:829-835.

10. Mentlein R. Dipeptidyl-peptidase IV (CD26) - role in the inactivation of regulatory peptides. Regul Pept. 1999;85:9-24.

11. Ahrén B, Simonsson E, Larsson H, et al. Inhibition of dipeptidyl peptidase IV improves metabolic control over a 4-week study period in type 2 diabetes. Diabetes Care. 2002;25:869-875.

12. Thomas L, Eckhardt M, Langkopf E, Tadayyon M, Himmelsbach F, Mark M. (R)-8-(3-amino-piperidin-1-yl)-7-but-2-ynyl-3-methyl-1-(4-methylquinazolin-2-ylmethyl)-3,7-dihydro-purine-2,6-dione (BI 1356), a novel xanthine-based dipeptidyl peptidase 4 inhibitor, has a superior potency and longer duration of action compared with other dipeptidyl peptidase-4 inhibitors. J Pharmacol Exp Ther. 2008;325:175-182.

13. Eckhardt M, Hauel N, Himmelsbach F, et al. 3,5-Dihydro-imidazo[4,5-d] pyridazin-4-ones: a class of potent DPP-4 inhibitors. Bioorg Med Chem Lett. 2008;18:3158-3162.

14. Gallwitz B. Small molecule dipeptidylpeptidase IV inhibitors under investigation for diabetes mellitus therapy. Expert Opin Investig Drugs. 2011;20:723-732.

15. Eckhardt M, Langkopf E, Mark M, et al. 8-(3-(R)-aminopiperidin1-yl)-7-but-2-ynyl-3-methyl-1-(4-methyl-quinazolin-2-ylme thyl)3,7-dihydropurine-2,6-dione (BI 1356), a highly potent, selective, long-acting, and orally bioavailable DPP-4 inhibitor for the treatment of type 2 diabetes. J Med Chem. 2007;50:6450-6453.

16. Deacon CF, Holst JJ. Linagliptin, a xanthine-based dipeptidyl peptidase-4 inhibitor with an unusual profile for the treatment of type 2 diabetes. Expert Opin Investig Drugs. 2010;19:133-140.

17. He YL, Sadler BM, Sabo R. The absolute oral bioavailability and population-based pharmacokinetic modelling of a novel dipeptidylpeptidase-IV inhibitor, vildagliptin, in healthy volunteers. Clin Pharmacokinet. 2007;46:787-802.

18. Herman GA, Stein PP, Thornberry NA, Wagner JA. Dipeptidyl peptidase-4 inhibitors for the treatment of type 2 diabetes: focus on sitagliptin. Clin Pharmacol Ther. 2007;81:761-767.

19. Huttner S, Graefe-Mody EU, Withopf B, Ring A, Dugi KA. Safety, tolerability, pharmacokinetics, and pharmacodynamics of single oral doses of BI 1356, an inhibitor of dipeptidyl peptidase 4 , in healthy male volunteers. J Clin Pharmacol. 2008;48:1171-1178.

20. Fuchs H, Binder R, Greischel A. Tissue distribution of the novel DPP-4 inhibitor BI 1356 is dominated by saturable binding to its target in rats. Biopharm Drug Dispos. 2090;30:229-240.

21. Fuchs H, Tillement JP, Urien S, Greischel A, Roth W. Concentrationdependent plasma protein binding of the novel dipeptidyl peptidase 4 inhibitor BI 1356 due to saturable binding to its target in plasma of mice, rats and humans. J Pharm Pharmacol. 2009;61:55-62.

22. Heise T, Graefe-Mody EU, Hüttner S, Ring A, Trommeshauser D, Dugi KA. Pharmacokinetics, pharmacodynamics and tolerability of multiple oral doses of linagliptin, a dipeptidyl peptidase-4 inhibitor in male type 2 diabetes patients. Diabetes Obes Metab. 2009;11: 786-794.

23. Horie Y, Kanada S, Watada H, et al. Pharmacokinetic, pharmacodynamic, and tolerability profiles of the dipeptidyl peptidase-4 inhibitor linagliptin: a 4-week multicenter, randomized, double-blind, placebocontrolled phase IIa study in Japanese type 2 diabetes patients. Clin Ther. 2011;33:973-989. 
24. Graefe-Mody EU, Padula S, Ring A, Withopf B, Dugi KA. Evaluation of the potential for steady-state pharmacokinetic and pharmacodynamic interactions between the DPP-4 inhibitor linagliptin and metformin in healthy subjects. Curr Med Res Opin. 2009;25:1963-1972.

25. Graefe-Mody EU, Jungnik A, Ring A, Woerle HJ, Dugi KA. Evaluation of the pharmacokinetic interaction between the dipeptidyl peptidase-4 inhibitor linagliptin and pioglitazone in healthy volunteers. Int J Clin Pharmacol Ther. 2010;48:652-661.

26. Friedrich C, Ring A, Brand T, Sennewald R, Graefe-Mody EU, Woerle HJ. Evaluation of the pharmacokinetic interaction after multiple oral doses of linagliptin and digoxin in healthy volunteers. Eur J Drug Metab Pharmacokinet. 2011;36:17-24.

27. Graefe-Mody U, Rose P, Ring A, Zander K, Iovino M, Woerle HJ. Assessment of the pharmacokinetic interaction between the novel DPP-4 inhibitor linagliptin and a sulfonylurea, glyburide, in healthy subjects. Drug Metab Pharmacokinet. 2011;26:123-129.

28. Friedrich C, Metzmann K, Rose P, Matteus M, Pinnetti S, Woerle HJ Pharmacokinetics and pharmacodynamics of BI10773, a sodium glucose cotransporter-2 (SGLT-2) inhibitor, and linagliptin, a dipeptidyl peptidase-4 (DPP-4) inhibitor, following co-administration in healthy volunteers. Diabetes. 2011;60(Suppl 1):2327-PO.

29. Del Prato S, Barnett AH, Huisman H, Neubacher D, Woerle HJ, Dugi KA. Effect of linagliptin monotherapy on glycaemic control and markers of beta-cell function in patients with inadequately controlled type 2 diabetes: a randomized controlled trial. Diabetes Obes Metab. 2011;13:258-267.

30. Kawamori R, Inagaki N, Araki E, et al. Linagliptin monotherapy provides superior glycaemic control versus placebo or voglibose with comparable safety in Japanese patients with type 2 diabetes: a randomized, placebo and active comparator-controlled, double-blind study. Diabetes Obes Metab. 2012;14:348-357.

31. Taskinen MR, Rosenstock J, Tamminen I, et al. Safety and efficacy of linagliptin as add-on therapy to metformin in patients with type 2 diabetes: a randomized, double-blind, placebo-controlled study. Diabetes Obes Metab. 2011;13:65-74.

32. Owens DR, Swallow R, Dugi KA, Woerle HJ. Efficacy and safety of linagliptin in persons with type 2 diabetes inadequately controlled by a combination of metformin and sulphonylurea: a 24-week randomized study. Diabet Med. 2011;28:1352-1361.

33. Gallwitz B, Rosenstock J, Rauch T, et al. 2-year efficacy and safety of linagliptin compared with glimepiride in patients with type 2 diabetes inadequately controlled on metformin: a randomised, double-blind, non-inferiority trial. Lancet. 2012;380:475-483.
34. Haak T, Meinicke T, Jones R, Weber S, von Eynatten M, Woerle HJ. Initial combination of linagliptin and metformin improves glycaemic control in type 2 diabetes: a randomized, double-blind, placebocontrolled study. Diabetes Obes Metab. 2012;14:565-574.

35. Gomis R, Espadero RM, Jones R, Woerle HJ, Dugi KA. Efficacy and safety of initial combination therapy with linagliptin and pioglitazone in patients with inadequately controlled type 2 diabetes: a randomized, double-blind, placebo-controlled study. Diabetes Obes Metab. 2011;13:653-661.

36. Schernthaner G, Barnett AH, Emser A, et al. Safety and tolerability of linagliptin: a pooled analysis of data from randomized controlled trials in 3572 patients with type 2 diabetes mellitus. Diabetes Obes Metab. 2012; $14: 470-478$.

37. Yazbeck R, Howarth GS, Abbott CA. Dipeptidyl peptidase inhibitors, an emerging drug class for inflammatory disease? Trends Pharmacol Sci. 2009;30:600-607.

38. Schürmann C, Linke A, Engelmann-Pilger K, et al. The dipeptidyl peptidase-4 inhibitor linagliptin attenuates inflammation and accelerates epithelialization in wounds of diabetic ob/ob mice. J Pharmacol Exp Ther. 2012;342:71-80.

39. Klein T, Niessen HG, Ittrich C, et al. Evaluation of body fat composition after linagliptin treatment in a rat model of diet-induced obesity: a magnetic resonance spectroscopy study in comparison with sibutramine. Diabetes Obes Metab. 2012;14:1050-1053.

40. Hocher B, Sharkovska Y, Mark M, Klein T, Pfab T. The novel DPP-4 inhibitors linagliptin and BI 14361 reduce infarct size after myocardial ischemia/reperfusion in rats. Int $J$ Cardiol. Epub January 2, 2012.

41. Johansen OE, Neubacher D, von Eynatten M, Patel S, Woerle HJ. Cardiovascular safety of linagliptin in patients with type 2 diabetes mellitus: a pre-specified, prospective, and adjudicated meta-analysis of a phase 3 programme. Cardiovasc Diabetol. 2012;11:3.

42. Gallwitz B. Linagliptin-a novel dipeptidyl peptidase inhibitor for type 2 diabetes therapy. Clin Med Insights Endocrinol Diabetes. 2012;5:1-11.

43. Scheen AJ, Paquot N. Gliptin versus a sulphonylurea as add-on to metformin. Lancet. 2012;380:450-452.

44. Scheen AJ, Van Gaal LF. Linagliptin (Trajenta): a selective DPP-4 inhibitor with limited renal elimination. Rev Med Liege. 2012 67:91-97. French.

Z Diabetes, Metabolic Syndrome and Obesity: Targets and Therapy

\section{Publish your work in this journal}

Diabetes, Metabolic Syndrome and Obesity: Targets and Therapy is an international, peer-reviewed open-access journal committed to the rapid publication of the latest laboratory and clinical findings in the fields of diabetes, metabolic syndrome and obesity research. Original research, review, case reports, hypothesis formation, expert opinion and commentaries are all considered for publication. The manuscript management system is completely online and includes a very quick and fair peer-review system, which is all easy to use. Visit http://www.dovepress.com/testimonials.php to read real quotes from published authors. 